\title{
Clinical study comparing outcome of post in vitro fertilisation triplet pregnancy reduced to twins versus non reduced in vitro fertilisation triplet pregnancies
}

\author{
Sanjay Kumar Sharma, Reema Kumar Bhatt*, Anupam Kapur, Shakti Panda
}

Department of Obstetrics and Gynecology, Army Hospital Research and Referral, New Delhi, India

Received: 10 September 2019

Accepted: 01 October 2019

\section{*Correspondence:}

Dr. Reema Kumar Bhatt,

E-mail: reemakamalbhatt@yahoo.co.in

Copyright: (C) the author(s), publisher and licensee Medip Academy. This is an open-access article distributed under the terms of the Creative Commons Attribution Non-Commercial License, which permits unrestricted non-commercial use, distribution, and reproduction in any medium, provided the original work is properly cited.

\begin{abstract}
Background: There has been an upsurge in the number of multiple pregnancies with its attributability to increasing use of artificial reproductive techniques. To study clinical outcome of post IVF triplet pregnancy reduced to twin pregnancies compared to those without triplet reduction.

Methods: Hospital designed comparative study. 31 subjects were studied for comparative study design with triplets obtained after infertility treatment (assisted post-IVF). Out of 31, 15 subjects were expectantly managed who refused reduction while 16 subjects chose reduction to twins. Outcomes like prematurity, complications in neonate, birth weight discordance, neonatal mortality and maternal complications were studied.

Results: The fetal (triplet) reduction group was associated with significant $(\mathrm{p}<0.002)$ higher neonatal birth weight as compared to non-reduced group. The fetal reduction group had significantly lower incidence of prematurity and neonatal complications like hyperbilirubinemia, respiratory distress syndrome and neonatal sepsis. The maternal complications were also higher in nonreduced in terms of PPROM, gestational hypertension, gestational diabetes mellitus, intrahepatic cholestasis of pregnancy and gestational hypertension.

Conclusions: It is indicated that the reduction of triplet to twins is effective considering more complications with non-reduced group and hence reduction improves favorable pregnancy outcomes.
\end{abstract}

Keywords: Assisted reproduction, Pregnancy outcomes, Triplet reduction, Twin pregnancy

\section{INTRODUCTION}

There has been an upsurge in the number of multiple pregnancies with its attributability to increasing use of artificial reproductive techniques. ${ }^{1}$ There is always a dilemma in the minds of infertility couples to continue with triplet pregnancy in favour of reduction with the fear of the chance of loss of entire pregnancy following reduction. Triplet pregnancies have been controversial both in terms of counselling and management. ${ }^{2}$ Multifetal pregnancies, accounts for high risk of miscarriage, anemia, hypertensive disorders, hemorrhage, operative delivery, congenital malformations and postnatal illness. ${ }^{3}$
Due to high-risk nature of triplet pregnancy, women are often offered multifetal pregnancy reduction (MFPR). The literature does not guide convincingly on decision favouring multifetal pregnancy reduction versus expectant management leaving both patient and doctor in a dilemma. ${ }^{4,5}$

In general, the incidence of multifetal birth associated with infant mortality with the rate of $2.5 \%$ more than that of single birth. Prevention of such multiple pregnancies must be the primary concern considering significant impact on available medical and economic reources. ${ }^{6}$ 
Triplet reduction to twins has been reported as a therapeutic alternative approach to manage multifetal pregnancies. It can be performed in order to decrease the extreme prematurity, low birth weights infants, prenatal morbidity and mortality. ${ }^{7}$ This therapeutic reproductive approach has been shown to be safe and improve the surviving fetus outcomes. In most of the cases, reported (approx 23-26\%), by clinical human fertilization and Embryology authority (HFEA) showed that the triplet reduction has shown the significant increase in incidence of stable twins, conceived through IVF. ${ }^{8}$ Triplet reduction approaches are critically based on the use of embryotoxic agent and the duration of gestation period. It may undergo spontaneously or by manual trans-cervical and trans-abdominal echo-guided embryo puncture method. Pre-procedure examinations before reduction process is carried out to determine the accessibility and the anomalous fetus, if any. ${ }^{9}$

The present study aims to study subjects of triplet reduction into twins compared to those without reduction followed by the evaluation of critical outcomes. Such study and its outcome can be used to validate the clinical research on findings of the multifetal reduction. This study has provided an insight into the systemic collection of measurable outcomes during gestation and after delivery of reduced subjects as compared to the nonreduced groups.

\section{METHODS}

This clinical study included all the patients, who underwent assisted reproduction IVF treatment. A total of 31 subjects with post-IVF triplets were studied and were divided into two main groups. Group I $(n=15)$ pregnancies with control non-reduced twins who did not choose reduction in spite of counselling and group-II $(n=16)$ pregnancies chose to undergo fetal reduction after counselling. For study outcomes, the records containing full gestation and birth data were analyzed. The subjects underwent manual trans-abdominal fetal reduction and measurable outcomes were compared with non-reduced groups (Figure 1).

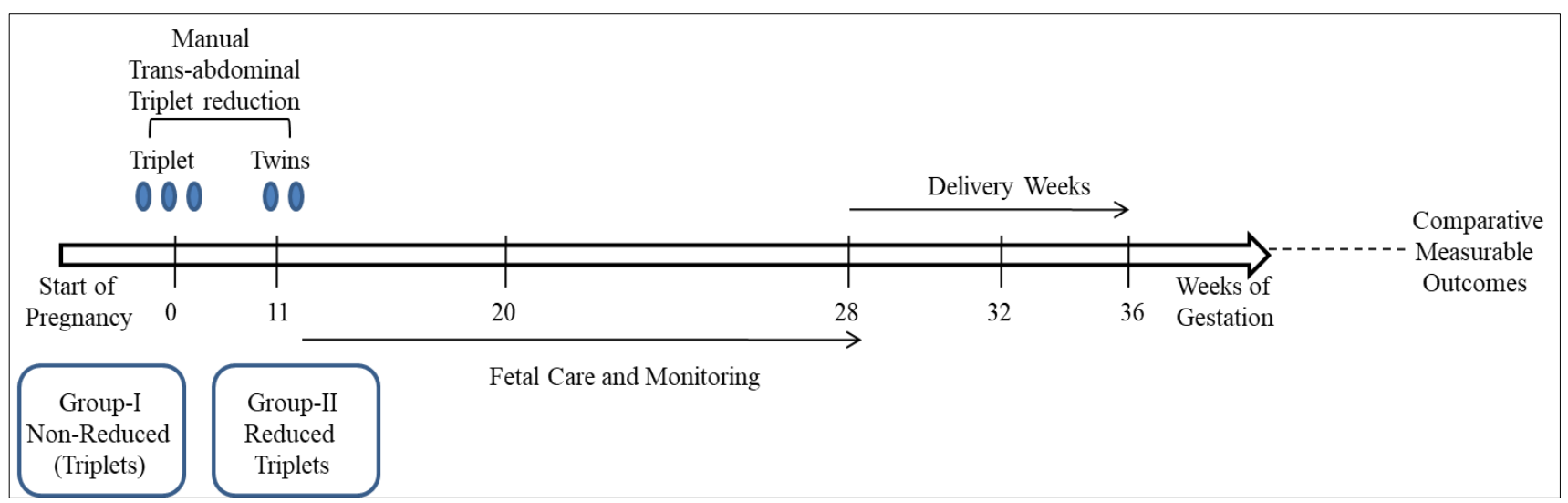

Figure 1: Schematic diagram of the triplet to twins reduction study at tertiary army hospital.

\section{Fetal reduction}

Fetal reduction of Group II subjects was performed between 11-13 weeks of gestation, mean period of $11 \pm 2.0$ week after Nuchal Translucency scan and determination of chorionicity (all trichorionic, triaminiotic pregnancies were included in the study) prior to the procedure. Using trans-abdominal technique an ultrasound examination was performed prior to the procedure to know the number of fetus, cardiac activity, to establish the relationship of the gestational sacs to each other and also to determine and plan which of the fetuses were most accessible to needle insertion. MFR procedure was carried out between 11 to 13 weeks period of gestation.

The fetus which was easily accessible to the needle in transabdominal approach usually that closest to the anterior uterine wall and/or the fundus was reduced while that near the cervix was avoided. However, in case of anomalous fetus it was the one subjected to reduction sparing the other two. Pre-procedure single dose of antibiotic and single dose hydroxy progesterone caproate was given to all the patients. Under ultrasound guidance, using 21-gauge spinal needle, the procedure was performed trans-abdominal (TA) by injection of 2-3 $\mathrm{ml}$ of potassium chloride $(2 \mathrm{meq} / \mathrm{ml})$ into the fetal thorax. Asystole was seen within 1-2 min of injection of potassium chloride however more potassium chloride was used if asystole was not achieved.

For data collection, the period of gestation for all the members of Group I and II were categorized in three subgroups (a) between 28 to 32 weeks; (b) between 32 to 36 weeks; and (c) >36 weeks respectively. The data for 
measurable outcomes were collected for total gestation age, gestation complications, mean birth weight at delivery, complications of neonatal and mortality rates.

\section{Statistical analysis}

Student t-test was performed to compare patient's median gestational ages at delivery for non-reduced and reduced twins. Relative risk (RR) calculations were performed to study the change in birth weights and complications in the pregnancies of the reduced and non-reduced groups at the confidence limit (CI) of 95\%. All the analysis was performed using SPSS software version 8.0.

\section{RESULTS}

\section{Fetal reduction outcome}

All the couples in reduced and non-reduced groups were conceived after reproductive infertility treatment. The median gestation for the triplet to twin reduction was 11 weeks $( \pm 2.0)$; however, the median gestation at the time of delivery showed significant $(\mathrm{p}<0.005)$ change in the reduced group as compared to non-reduced group (35.3 weeks) as shown in Table 1. It showed the relative gestational difference of 2.5 weeks in reduced group as compared to non-reduced. The birth age distribution at delivery was divided into three subgroups, also shown in Table 1 (sub-groups (a) between 28 to 32 weeks; (b) between 32 to 36 weeks; and (c) >36 weeks). In the nonreduced groups, 05 deliveries were recorded in median week; the corresponding deliveries for triplet reduced group were recorded significantly higher as compared to non-reduced with 11 deliveries in 35 weeks of gestation.

\section{Pregnancies gestation complication record}

Complications were studied during the pregnancies were listed in Table 2. Higher incidence of Anemia, GDM, IHCP, UTI, PPROM, G.HTN cases in the non-reduced group was found to be significantly higher as compared to reduced $(\mathrm{p}<0.002)$. Subsequently, the cases of preterm labor in the non-reduced group (05 infants below the mean gestation period of 35 weeks) were also recorded significantly higher as compared to reduced group $(\mathrm{p}<0.005)(\mathrm{RR} 0.53,95 \% \mathrm{CI})$.

Table 1: Outcome according to the total birth during the three subgroups categories of gestational period (subgroups (a) between 28 to 32 weeks; (b) between 32 to 36 weeks; and (c) >36 weeks).

\begin{tabular}{|llllll|}
\hline Groups & Name of group & $\begin{array}{l}\text { Mean } \\
\text { gestation } \\
\text { period }\end{array}$ & $\begin{array}{l}\text { Birth between 28 } \\
\text { to 32 weeks } \\
\text { (Subgroup a) }\end{array}$ & $\begin{array}{l}\text { Birth between 32 to } \\
\mathbf{3 6} \text { weeks } \\
\text { (Subgroup b) }\end{array}$ & $\begin{array}{l}\text { Birth in }>36 \text { weeks } \\
\text { (Subgroup c) }\end{array}$ \\
\hline Group I $(\mathrm{n}=15)$ & Non-reduced twins & 33 weeks & 09 & 05 & 01 \\
\hline Group II $(\mathrm{n}=16)$ & $\begin{array}{l}\text { Reduced twins } \\
\text { (trans-abdominal) }\end{array}$ & 35.3 weeks & 04 & 11 & 00 \\
\hline
\end{tabular}

Table 2: Birth and neonatal data of non-reduced and reduced groups.

\begin{tabular}{|llll|}
\hline Sr. no. & Measurable outcome & Non-reduced twins $(\mathbf{n = 1 5})$ & Reduced twins (n=16) \\
\hline 1 & Gestation time of triplet reduction & Nil & $11 \pm 2.0$ weeks \\
\hline 2 & Number of cervical encirclage cases & 05 & 02 \\
\hline 3 & Gestation complications & 01 & 0 \\
\hline & Bleeding & 02 & 0 \\
\hline UTI & 06 & 0 \\
\hline & G.HTN & 03 & 0 \\
\hline & Anemia & 0 & 0 \\
\hline & Fever & 02 & 01 \\
\hline & GDM & 02 & 0 \\
\hline & Preterm labour (any delivery before 35 weeks is & 05 & 0 \\
\hline preterm) & 02 & 0 \\
\hline & PPROM & 02 & 0 \\
\hline PROM & Neonatal mortality & 0 & 0 \\
\hline 5 & Neonatal complications & 01 & 0 \\
\hline & Hyperbilirubinemia & 02 & 0 \\
\hline & RDS & 03 & 0 \\
\hline
\end{tabular}


Table 3: The mean birth weights of non-reduced and reduced twins at different gestation weeks.

\begin{tabular}{|lllll|}
\hline Sr. no. & Delivery weeks & Non-reduced twins $(\mathbf{n}=\mathbf{1 5})$ & Reduced twins $(\mathbf{n = 1 6})$ \\
\hline 1 & Birth between 28 to 32 weeks (Subgroup a) & $1.37 \mathrm{kgs}$ & $1.59 \mathrm{kgs}$ \\
\hline 2 & Birth between 32 to 36 weeks (Subgroup b) & $1.30 \mathrm{kgs}$ & $1.89 \mathrm{kgs}$ \\
\hline 3 & Birth in $>36$ weeks (Subgroup c) & $1.5 \mathrm{kgs}$ & - \\
\hline
\end{tabular}

\section{Mean birth weight}

The mean birth weight of the infants in reduced twins corresponding to different gestation periods was found to be significantly $(\mathrm{p}<0.05)$ higher with $1.84 \pm 1.0 \mathrm{kgs}$ weight, compared with $1.39 \pm 0.67 \mathrm{kgs}$ in the non-reduced group. The mean body weight of both the groups at different gestation time period showed significant variation $(\mathrm{p}=0.02)$, as shown in Table 3 . No significant deaths in any group was seen though one infant loss and single delivery in $16^{\text {th }}$ week gestation found in the nonreduced group.

\section{Neonatal complications}

Stratifying neonatal complications showed significant difference in occurrence $(\mathrm{p}<0.005)$ within the nonreduced infants. Complications such as Hyperbilirubinemia (12.5\%), RDS (18.75\%) and neonatal sepsis $(6 \%)$ were observed in non-reduced twins. No such complications were observed in reduced infants.

\section{DISCUSSION}

Multifetal reduction of triplets conceived through ARTs has been performed very usually to minimize the pregnancy complications. The multifetal reduction technique has helped to reduce high order pregnancies to twins with the aim of improving outcomes both neonatal and maternal. ${ }^{10}$ It also reduces the extreme prematurity along with the risk of fatal outcomes. However, the decision of multifetal reduction especially in ART pregnancies to twins is an uneasy and difficult decision as it involves the risk of loss of entire pregnancy that cannot be predicted accurately. ${ }^{11}$ High order pregnancies sometimes carries a higher risk of prenatal outcomes, significant complications of prematurity and most common is preterm labour. ${ }^{12}$ The data of this study showed that the outcome of triplet pregnancies reduced to twins differ substantially from the non-reduced group. The information regarding the outcome of twin pregnancies after reduction is based on limited subjects. We also aimed to address the pregnancy outcomes and birth weights resulting after reduction as compared with non-reduced group.

Herein, the subjects were allocated to the reduction intervention group were those who chose to proceed with multifetal reduction transabdominally $(n=16)$, whereas subjects allocated to the non-reduced control group were those who declined triplet reduction $(n=15)$. An important observation found in the group of reduced pregnancies was that they were delivered above 35 weeks gestation. However, the non-reduced pregnancies mean delivery period was found to be 33 weeks. It also indicated that the newborns in the reduced group showed significantly higher mean birth weight at the delivery as compared with the non-reduced group. This indicates that reduction improves outcome with lower rate of gestational complications. More importantly, several other clinical groups have shown comparable results regarding the overall rate of risks associated with multifetal pregnancy without reduction. ${ }^{13}$

Secondary remarkable outcome of the data has shown that the subjects in the multifetal reduction group were likely to have less gestational complications (RR 0.53, 95\% CI). Significant difference was also seen between the two groups for preterm labour (RR 1.61, 95\% CI). It was found to be less in reduced group as compared to non-reduced. It showed that non reduced group has higher preterm birth and a delivery before 28th week of gestation along with one fetal loss. This indicated that the multifetal pregnancy is a strong risk factor for preterm birth and remains the most serious complications, as compared to non-reduced. ${ }^{7,14}$ Therefore, the assisted reproductive triplet reduction treatment is effective in reducing the rate of prematurity in multifetal gestation. ${ }^{15}$ Moreover, the extreme cases have also occurred frequently in the non-reduced groups as compared to reduced ones (data on hospital records).

Our study also demonstrated the decrease in adverse neonatal outcomes that related to infant morbidity among the reduced group infants. Among the non-reduced group, over two third of the cases, showed complications such as Hyperbilirubinemia, RDS and neonatal sepsis recorded in the babies. This indicates that the nonreduced infants fail to follow the true growth curve and have suboptimal growth with short term complications. ${ }^{16}$ These neonatal complications have already been noted by other authors also associated with non-reduced twins. ${ }^{17}$

\section{CONCLUSION}

In conclusion, the overall characteristics of new-borns of reduced were different as compared to non-reduced group is with better outcomes in reduced group. Triplets or high order pregnancies have been increasing due to increasing resort to ART techniques as method of conception. This study could be the reflection of daily clinical practice of subjects taking ARTs. Furthermore, this data is restricted 
to short term clinical outcomes, which more important for predicting survival rates. The rate of complications in non-reduced group appear higher to reduced subjects, with less suboptimal growth rates. Triplet pregnancy can be offered reduction with improved neonatal and maternal outcome with adequate counselling of the associated complications and improvement in outcome with reduction.

\section{Funding: No funding sources}

Conflict of interest: None declared

Ethical approval: The study was approved by the Institutional Ethics Committee

\section{REFERENCES}

1. ACOG Committee opinion no. 719: Multifetal pregnancy reduction. Obstet Gynecol. 2017;130(3):670-1.

2. Evans MI, Britt DW. Multifetal pregnancy reduction: evolution of the ethical arguments. Semin Reprod Med. 2010;28(4):295-302.

3. Murray SR, Norman JE. Multiple pregnancies following assisted reproductive technologies: a happy consequence or double trouble?. Seminars in Fetal Neonatal Med. 2014;19(4):2014.

4. Yaron Y, Bryant-Greenwood PK, Dave N, Moldenhauer JS, Kramer RL, Johnson MP, Evans MI. Multifetal pregnancy reductions of triplets to twins: comparison with nonreduced triplets and twins. Am J Obstet Gynecol. 1999;180(5):1268-71.

5. Ozturk, Ozkan, Templeton A. Multiple pregnancy in assisted reproduction techniques. Current Practice and Controversies in Assisted Reproduction. World Health Organization, Geneva, Switzerland. 2002:220-234.

6. Little CM. One consequence of infertility treatment: multifetal pregnancy. The Am J Maternal/Child Nurs. 2010;35:150-5.

7. Lipitz, Shlomo. The improving outcome of triplet pregnancies. Am J Obstet Gynecol. 1989;161:127984.

8. Mairead, Bhattacharya S. Epidemiology of multiple pregnancy and the effect of assisted conception. Seminars Fetal Neonatal Med. 2010;15:6
9. Engmann L, Maconochie N, Tan SL, Bekir J. Trends in the incidence of births and multiple births and the factors that determine the probability of multiple birth after IVF treatment. Human Reprod. 2001;16:2598-605.

10. Dodd J, Crowther C. Multifetal pregnancy reduction of triplet and higher-order multiple pregnancies to twins. Fertility Sterility. 2004;81:1420-2.

11. Wimalasundera RC, Trew G, Fisk NM. Reducing the incidence of twins and triplets. Best Pract Res Clin Obstet Gynaecol. 2003;17:309-29.

12. Dey M, Saraswat M. Outcomes of multifetal reduction: a hospital-based study. The J Obstet Gynecol India. 2018;68:264-9.

13. Dickey RP, Taylor SN, Lu PY, Sartor BM, Storment JM, Rye PH, et al. Spontaneous reduction of multiple pregnancy: incidence and effect on outcome. Am J Obstet Gynecol. 2002;186:77-83.

14. Squires EL, McClain MG, Ginther OJ, McKinnon AO. Spontaneous multiple ovulation in the mare and its effect on the incidence of twin embryo collections. Theriogenol. 1987;28(5):609-13.

15. Practice Committee of the American Society for Reproductive Medicine. Multiple gestation associated with infertility therapy: an American Society for Reproductive Medicine Practice Committee opinion. Fert Steri. 2012;97:825-34.

16. Evans MI, Littmann L, Louis LS, LeBlanc L, Addis J, Johnson MP, et al. Evolving patterns of iatrogenic multifetal pregnancy generation: implications for aggressiveness of infertility treatments. Am J Obstet Gynecol. 19995;172:1750-5.

17. Pons JC, Charlemaine C, Dubreuil E, Papiernik E, Frydman R. Management and outcome of triplet pregnancy. Eu J Obstet Gynecol Reprod Biol. 1998;76:131-9.

Cite this article as: Sharma SK, Bhatt RK, Kapur A, Panda S. Clinical study comparing outcome of post in vitro fertilisation triplet pregnancy reduced to twins versus non reduced in vitro fertilisation triplet pregnancies. Int J Reprod Contracept Obstet Gynecol 2019;8:4191-5. 